\title{
The worth emphasizing surgical technique: ureteropyelostomy to manage urinary tract complications in renal transplantation: two case reports
}

\author{
Chanjoong Choi, Chanjoong Choi, Moonsang Ahn
}

Department of Surgery-Transplantation, Chungnam National University Hospital, Daejeon, Korea

Background: Ureteric stricture after renal transplantation can lead to allograft kidney damage, prompt treatment is necessary. The ureteropyelostomy using the recipient's ipsilateral native ureter is the best choice of several treatments that can salvage an allograft kidney. The aim of this report proves that the ureteropyelostomy using a native ureter is the surgical technique to be feasible management of urinary tract complications after renal transplantation. Two patients who failed conservative treatment of urinary stenosis after renal transplantation were reviewed using electronic medical records, radiologic images, and surgery.

Case reports: (Case 1) A 41-year-old male undergone 2nd renal transplantation in 2017. Initial transplantation was performed in 1992, with allograft in the right iliac fossa. At the postoperative 18 days, he presented an abdominal pain with oozing on the surgical incision site. On computed tomography, there was a ureteral rupture and perirenal hematoma of the allograft. The ureteropyelostomy using a native ipsilateral ureter was performed successfully without any complications such as ureteral necrosis, urinary leakage, and urinary stricture. After 3 years of follow-up, he had a well-functioning allograft with a serum creatinine level of $1.59 \mathrm{mg} / \mathrm{dL}$. (Case 2) A 52-year-old male underwent renal transplantation in March 2018. At 5 months after surgery, oliguria and hydronephrosis occurred due to the ureter stone of the graft. The patient underwent percutaneous nephrostomy and ureterolithotomy, and the double-J catheter was inserted. In November 2020, because of urinary tract infection and aggravated stricture of the ureter, ureteropyelostomy using a native ureter was performed successfully except for minor tearing of the renal artery. After 3 weeks of follow-up, he had a well-functioning allograft with a serum creatinine level of $0.98 \mathrm{mg} / \mathrm{dL}$.

Conclusions: The ureteropyelostomy using a native ipsilateral ureter can be a safe and feasible surgical technique that treated urinary complications after renal transplantation and resulted in good graft and patient survival.

Corresponding author: Moonsang Ahn

E-mail:amsgs@yahoo.com

(c) The Korean Society for Transplantation

This is an Open Access article distributed under the terms of the Creative Commons Attribution Non-Commercial License (http://creativecommons.org/licenses/by-nc/4.0/) which permits unrestricted non-commercial use, distribution, and reproduction in any medium, provided the original work is properly cited. 